\title{
Optimizing the Total Cost of an E-waste Reverse Supply Chain Considering Transportation Risk
}

\author{
Linh Thi Truc Doan \\ School of Engineering \\ University of South Australia, Australia \\ Department of Industrial Management \\ Can Tho University, Vietnam \\ Email: linh.doan@mymail.unisa.edu.au (Corresponding Author) \\ Yousef Amer \\ School of Engineering \\ University of South Australia, Australia \\ Sang- Heon Lee \\ School of Engineering \\ University of South Australia, Australia \\ Phan Nguyen Ky Phuc \\ Department of Industrial System Engineering \\ Ho Chi Minh International University, Vietnam
}

\begin{abstract}
Due to technological boom, the quantity of electronic goods is significantly growing. After their useful life, they become e-waste which has considerable impacts on the environment and society. To mitigate the issue, the reverse supply chain (RSC) has been investigated to reuse components or recycle raw materials contained in e-waste. The total cost of RSC operation is one of the vital issues which has been receiving more attention from both industry and academia. The existing research concentrates on minimizing the overall cost of the system like transportation, operating, disposal and fixed costs. However, risks normally involved during the transportation of e-waste in RSC network has not been addressed. These risks might involve collection delays, breakdown of trucks, accidents and the variation of hazardous materials which can result in unexpected disruptions and significantly higher cost. Currently, there is no research incorporating transportation risk in RSC operation. This paper is aimed to develop a mathematical model for the total cost minimization of an ewaste RSC system with consideration of transportation risk. A mixed integer linear programming is applied in the proposed model and solved by an optimization software. To illustrate the applicability of the proposed model, a numerical example is also examined. The results of this paper can decide the optimal locations for treatment centers and the flow of used products or components delivered within an e-waste RSC network. This result can support managers to design an e-waste RSC network whilst transportation risk factors are considered.
\end{abstract}

Keywords: e-waste, mixed integer linear programming, reverse supply chain, transportation risk

\section{INTRODUCTION}

The amount of e-waste is rapidly increasing with the generation of 20-50 million tons, and a growth rate of $3 \%$ to $5 \%$ annually (Cucchiella et al., 2015). This rate is approximately three times faster compared to other waste streams (Singh et al., 2016). The reason is that the lifetime of many electronic devices has been considerably shortened due to technological advancement, attractive designs of electronic products, and compatibility problems (Kiddee et al., 2013). For instance, the average lifetime of a new computer in India is decreasing from 7 years to 4 years (Dwivedy and Mittal, 2010). The huge amount of e-waste leads to significant environmental issues that require global and national attention. The large quantity of e-waste in Guiyu, China, for example, is manually processed with improper methods for a long period that has influences on the quality of water, air, soil and human health (Sthiannopkao and Wong, 2013). One of the effective ways to mitigate the environmental effect of e-waste is to implement reverse supply chain (RSC) to gain recycled materials or reusable parts from such waste streams (Rahman and Subramanian, 2012). The scarcity of raw materials, sustainable development, and environmental regulations create RSC operation which makes the recovery of returned products and materials more attractive (Rahman and Subramanian, 2012, Dowlatshahi, 2000, Nagalingam et al., 2013, Chandiran, 2014)

The RSC operation may require a large initial investment for establishing collection areas, remanufacturing, and recycling facilities (Govindan and Soleimani, 2017). Hence, studies on total cost minimization 
of RSC system have been of interest for researchers and managers (Rogers et al., 2012, Dat et al., 2012, Gomes et al., 2011, Mahmoudi and Fazlollahtabar, 2014, Kilic et al., 2015, John et al., 2017, Anish Sachdeva et al., 2015). In the literature of RSC modelling, mixed integer linear programming (MILP) formulation is one of the major tools used (John et al., 2017). A basic RSC model in the product recovery configuration was introduced by Fleischmann et al. (2001). The main objective function of the model was to minimize the total cost for a multi-tier, single-product, uncapacitated facility location model. To demonstrate the usefulness of the suggested model, two cases involving copier manufacturing and paper recycling were considered. Min and Ko (2008) also suggested a MILP and used Genetic Algorithm (GA) to address the RSC problems relating to the location of repair centers for third-party logistics companies. The model can assist the company to combine the existing forward supply chain with the RSC chain for return products. As a result, this allows a company to establish a whole supply chain process to manage returned products from the comprehensive aspect. Pishvaee et al. (2010) developed a MILP model for multi-echelon RSC networks in order to minimize fixed and transportation costs. To find out the nearoptimal solution for the large-size problem, they used a simulated annealing (SA) algorithm with special neighbourhood search mechanisms. To address the inventory and production planning issues in RSC operation, Gomes et al. (2011) presented a MILP model for recovery network of e-waste, which was used to determine the optimal locations for collection and sorting facilities. They concluded that the costs of recycling and transportation are the main factors in the establishment of this network. Regarding the variation of input values, Anish Sachdeva et al. (2015) suggested a mathematical model for multi-layer RSC and solved by Lingo software. Sensitivity analysis with the different input values was obtained, and the model can assist managers to have a better decision in designing RSC network.

It is clear that a supply chain consists of multiple organisations with many echelons of suppliers or customers, which can lead to several risks at different stages (Manoj Hudnurkar, 2017). In supply chain operations, risks can be defined as a potential fluctuation from the initial objective, which can lead to non-value added activities at various stages (Eldabee, 2015). Kumar et al. (2010) suggested a mathematical model to minimize the total cost with incorporating the various kinds of risks and their impacts on the forward supply chain. A study on supply chain risk management was conducted by Thun and Hoenig (2011) through investigation of 67 manufacturing companies in Germany. The research examined the primary risks in supply chain system and analysed their loss of occurrence and their consequences. Some main risks such as purchasing risks, transportation risks, demand risks and environmental risks were considered in the research. The result illustrates that most of supply chain risks come from inside supply chain which managers can mitigate these risks directly.

Based on literature review, it is found that risks are majorly analysed in a forward supply chain but rarely considered in a reverse supply chain. A recent study conducted by Sohani and Chaurasia (2016) is to examine risks related to RSC operation. The framework analysed the probability and impacts of those risks and suggested a possible way to reduce such risks to improve the flow of materials more effectively. In RSC system, earlier studies mainly consider investment, processing, disposal and transportation costs in the overall cost. According to Dat et al. (2012) and Gomes et al. (2011), transportation cost constitutes a large percentage of total cost for RSC network. Especially, e-waste contains a variety of dangerous substances like lead, cadmium, and mercury (Kiddee et al., 2013). Unlike other materials, the transportation of hazardous substances might leads to a potential risk to human health and environment (Fabiano et al., 2002). In spite of the low likelihood of accidents occurred, the consequences might be higher in the case of hazardous materials transportation (Yanık, 2015). To our best knowledge, transportation risk associated with RSC operation is not investigated in the existing research. Transportation risks can generally derive from shipping of toxic materials contained in e-waste which can affect the transportation and total costs (Fabiano et al., 2002). Therefore, the current models are insufficient to represent the real e-waste RSC model. Hence, this paper aims to develop a multi-product, multi-tier RSC model, especially for ewaste to minimize the total cost with transportation risk integrated.

The rest of this paper is organized as follows; Section 2 presents the problem description whereas Section 3 shows the model development. In Section 4, the numerical example is addressed to demonstrate the usefulness of the proposed model. Finally, conclusions and future work are provided in Section 5.

\section{PROBLEM DESCRIPTION}

Figure 1 shows the general e-waste reverse supply chain network consisting of 4 tiers.

As shown in Figure 1, the used products from retailers or consumers are first picked up at collection areas (K). After that, they are delivered to disassembly centers (D) where the used products are disassembled into different parts or materials. In the next step, some recyclable materials like metals, and plastics are sent to recycling centers (R) while broken or damaged items are delivered to remanufacturing centers (M). Hazardous materials or waste will be transported to disposal site (L) for special treatments. Finally, recyclable and renewable materials are transferred to demand and secondary markets respectively.

To establish the RSC model with transportation risk, the key assumptions used in this study are as follows:

- $\quad$ The cost parameters used in the proposed model are deterministic and predefined.

- The location of collection areas, disposal sites, secondary and demand markets are known in advance.

- $\quad$ The size of treatment centers is limited.

- The probability of the accident happening and the consequence of the accident are available.

The notations, decision variables, and parameters used in the proposed model are given in the below: 


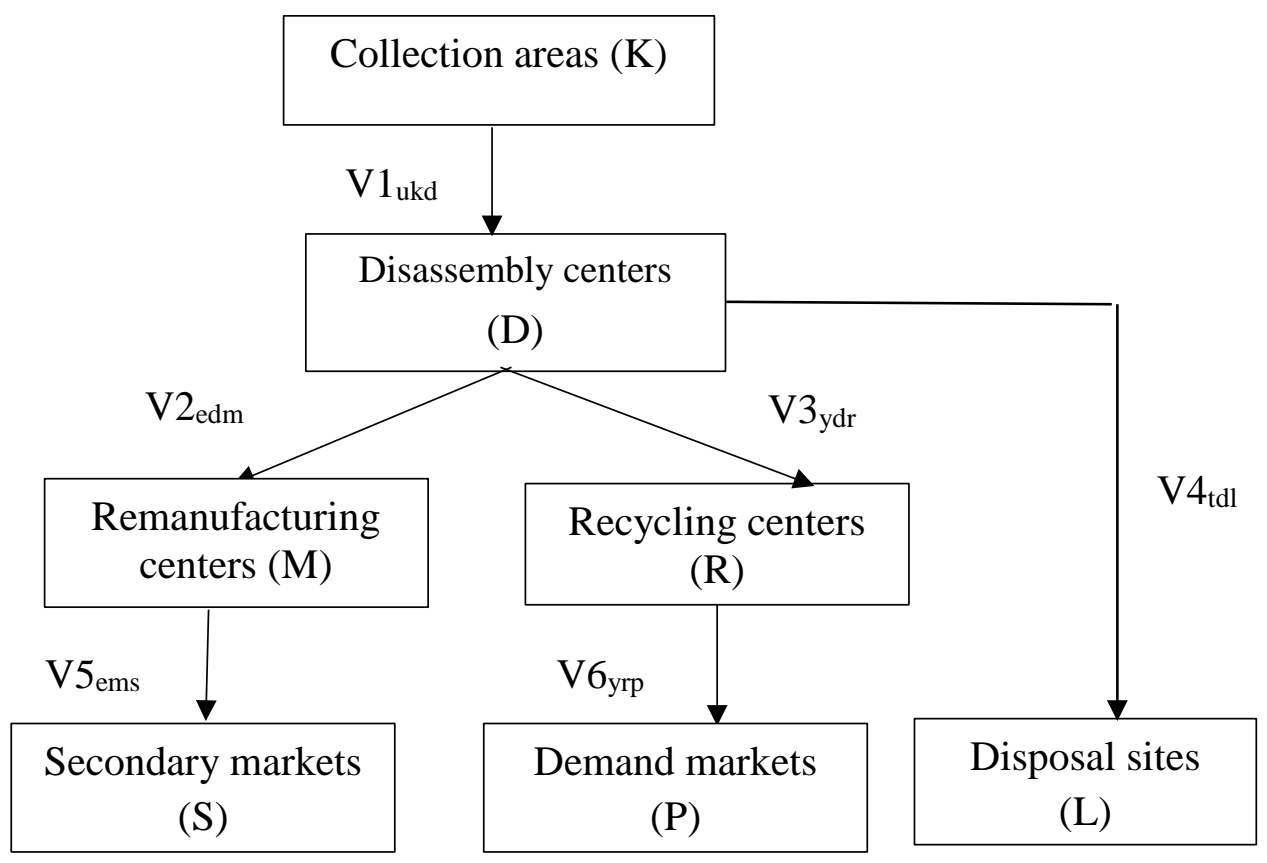

Figure 1 The e-waste reverse supply chain network

$V 1_{u k d} \quad$ The quantity of used product $u$ delivered from center $k$ to center $d$

$V 2_{\text {edm }}$ The quantity of reusable item $e$ delivered from center $d$ to center $m$

$V 3_{y d r}$ The quantity of recycling material $y$ delivered from center $d$ to center $r$

$V 4_{t d l}$ The quantity of hazardous material $t$ delivered from center $d$ to center $l$

$V 5_{e d u}$ The quantity of reusable item $e$ delivered from center $d$ to center $u$

$V 6_{y r p}$ The quantity of recycling material $y$ delivered from center $r$ to center $p$

$F_{d} \quad=1$ if a disassembly center is opened, $F_{d}=$ 0 otherwise

$F_{m} \quad=1$ if a remanufacturing center is opened, $F_{m}=0$ otherwise

$F_{r} \quad=1$ if a recycling center is opened, $F_{r}=0$ otherwise

Indices:

$k \quad$ Index of fixed pick-up sites, $k \in\{1 . . K\}$

$d$ Index of potential locations for disassembly centers, $d \in\{1 . . D\}$

$m$ Index of potential locations for remanufacturing centers, $m \in\{1 . . M\}$

$r$ Index of potential locations for recycling centers, $r \in\{1 . . R\}$

$s$ Index of fixed locations for secondary markets, $s \in\{1 . . S\}$

$p$ Index of fixed locations for demand markets, $p \in\{1 . . P\}$

$l \quad$ Index of fixed disposal site, $l \in\{1 . . L\}$

$u \quad$ Index of used products, $u \in\{1 . . U\}$

$e$ Index of reusable items, $e \in\{1 . . E\}$

$y$ Index of recycling materials, $y \in\{1 . . Y\}$

$t \quad$ Index of hazardous materials, $t \in\{1 . . T\}$
Decision variables:

Parameters:

$N_{u k} \quad$ The need of used product $u$ at collection site $k, k \in\{1 . . K\}$

$T u_{u} \quad$ The unit transportation cost of used product $u, u \in\{1 . . U\}$

$T e_{e} \quad$ The unit transportation cost of reusable items $e, e \in\{1 \ldots E\}$

$T y_{y} \quad$ The unit transportation cost of recycling materials $y, y \in\{1 . . Y\}$

$T t_{t} \quad$ The unit transportation cost of hazardous materials $t, t \in\{1 . . T\}$

$B C_{d} \quad$ Fixed cost of disassembly center $d$, $d \in\{1 . . D\}$

$B C_{m} \quad$ Fixed cost of remanufacturing center $m$, $m \in\{1 . . M\}$

$B C_{r} \quad$ Fixed cost of recycling center $r, r \in\{1 . . R\}$

$L C_{t l} \quad$ The unit cost of hazardous material $t$ at disposal site $l$

$R e_{e} \quad$ The unit revenue for reusable item $e$

$R y_{y} \quad$ The unit revenue for recycling material $y$

$O u_{u d} \quad$ The unit operating cost of used product $u, u \in\{1 . . U\}$ at treatment center $d$, $d \in\{1 . . D\}$

$O e_{e m} \quad$ The unit operating cost of reusable item $e, \mathrm{e} \in\{1 . . E\}$ at treatment center $m$, $m \in\{1 . . M\}$

$O y_{y r} \quad$ The unit operating cost of recycling material $y, y \in\{1 . . Y\}$ at treatment center $r, r \in\{1 . . R\}$

$B_{k d} \quad$ Distance between centers $k$ and $d$, $k \in\{1 . . K\}, d \in\{1 . . D\}$

$B_{d m} \quad$ Distance between centers $d$ and $m$, $d \in\{1 . . D\}, m \in\{1 . . M\}$

$B_{d r} \quad$ Distance between centers $d$ and $r$, $d \in\{1 . . D\}, r \in\{1 . . R\}$ 
$B_{d l} \quad$ Distance between centers $d$ and $l$, $\mathrm{d} \in\{1 . . D\}, l \in\{1 . . L\}$

$B_{m s} \quad$ Distance between centers $m$ and $s$, $m \in\{1 . . M\}, s \in\{1 . . S\}$

$B_{r p} \quad$ Distance between centers $r$ and $p$, $k \in\{1 . . K\}, d \in\{1 . . D\}$

$\alpha l_{e u} \quad$ The number of reusable item $e, e \in\{1 . . E\}$ obtained from the used product $u$, $u \in\{1 . . U\}$

$\alpha 2_{y u}$ The number of recycling material $y$, $y \in\{1 . . Y\}$ obtained from the used product $u, u \in\{1 . . U\}$

$\alpha 3_{t u}$ The number of hazardous materials $t$, $t \in\{1 . . T\}$ obtained from the used product $u, u \in\{1 . . U\}$

$\beta_{e} \quad$ The average percentage of renewable material $e$ obtained at remanufacturing center

$\beta y \quad$ The average percentage of recycling material $y$ obtained at recycling center

$\mathrm{Ne}_{e s} \quad$ Maximum need of reusable item $e$, $e \in\{1 . . E\}$ at secondary market $s$, $s \in\{1 . . S\}$

$N y_{y p} \quad$ Maximum need of recycling material $y$, $y \in\{1 . . Y\}$ at demand market $p, p \in\{1 . . P\}$

$C U_{u d}$ Maximum capacity of used product $u$, $u \in\{1 . . U\}$ at disassembly center $d$, $d \in\{1 . . D\}$

$C E_{\text {em }}$ Maximum capacity of reusable item $e$, $e \in\{1 . . E\}$ at remanufacturing center $m$, $m \in\{1 . . M\}$

$C Y_{y r} \quad$ Maximum capacity of recycling material $y, y \in\{1 . . Y\}$ at recycling center $r$, $r \in\{1 . . R\}$

$C T_{t l}$ Maximum capacity of hazardous material $t, t \in\{1 . . T\}$ at disposal site $l$, $l \in\{1 . . L\}$

$P O 1_{k d}$ The probability of occurrence of an accident on route $k$ to $d$

$P O 2_{d m}$ The probability of occurrence of an accident on route $d$ to $m$

$P O 3_{d r}$ The probability of occurrence of an accident on route $d$ to $r$

$P O 4_{d l}$ The probability of occurrence of an accident on route $d$ to $l$

$P O 5_{m s}$ The probability of occurrence of an accident on route $m$ to $s$

$P O 6_{r p}$ The probability of occurrence of an accident on route $r$ to $p$

$C O 1_{k d}$ The consequence of occurrence of an accident on route $k$ to $d$

$C O 2_{d m}$ The consequence of occurrence of an accident on route $d$ to $m$

$C O 3_{d r}$ The consequence of occurrence of an accident on route $d$ to $r$

CO4 $4_{d l}$ The consequence of occurrence of an accident on route $d$ to $l$

$C O 5_{m s}$ The consequence of occurrence of an accident on route $m$ to $s$

$C O 6_{r p}$ The consequence of occurrence of an accident on route $r$ to $p$
Note that the risk factors in the transportation are described as the probability of occurrences in $P O 1_{k d}$, $P O 2_{d m}, \ldots, P O 6_{r p}$ and the consequence of occurrences in $C O 1_{k d}, C O 2_{d m}, \ldots, C O 6_{r p}$ which are evaluated from the scale of 1 (lowest) to 10 (highest) adopted from (El Dabee et al., 2014).

\section{MODEL DEVELOPMENT}

The main objective of the proposed model is like to other existing approaches, to minimize the total cost (TC) shown in Eq.1. The first three terms in Eq.1 represent operating costs in disassembly, remanufacturing, and recycling facilities, respectively. The next three terms describe the fixed cost for establishing those treatment centers, respectively. The last term in the second line of Eq. 1 is the disposal cost for hazardous materials. The next six terms present the transportation cost between centers. The next terms (sixth line in Eq.1) indicate the revenue received from selling recovery materials and reusable items. The costs related to the transportation risks is presented in the last six terms. In this paper, the risk cost, for transportation risk, is calculated by multiplying the percentage of risk score and corresponding transportation cost. Transportation risks include transportation delays, the breakdown of trucks or the uncertainty of hazardous materials normally stemmed from delivering components or materials between nodes in the RSC network, which can result in higher transportation cost (Sheu, 2007).

To represent the established model as the real RSC model, the following constraints are considered in the model;

Subject to:

$$
\begin{aligned}
& \sum_{d=1}^{D} V 1_{u k d}=N_{u k}, \forall u, k \\
& \sum_{m=1}^{M} V 2_{e d m}=\sum_{u=1}^{U}\left(\alpha 1_{e u} \times \sum_{k=1}^{K} V 1_{u k d}\right), \quad \forall e, d \\
& \sum_{r=1}^{R} V 3_{y d r}=\sum_{u=1}^{U}\left(\alpha 2_{y u} \times \sum_{k=1}^{K} V 1_{u k d}\right), \quad \forall y, d \\
& \sum_{l=1}^{L} V 4_{t d l}=\sum_{u=1}^{U}\left(\alpha 3_{t u} \times \sum_{k=1}^{K} V 1_{u k d}\right), \quad \forall t, d \\
& \sum_{s=1}^{S} V 5_{e m s}=\beta_{e} \times \sum_{d=1}^{D} V 2_{e d m}, \quad \forall e, m \\
& \sum_{p=1}^{P} V 6_{y r p}=\beta_{y} \times \sum_{d=1}^{D} V 3_{y d r}, \quad \forall y, r
\end{aligned}
$$




$$
\begin{aligned}
& T C=\sum_{u=1}^{U} \sum_{k=1}^{K} \sum_{d=1}^{D} V 1_{u k d} \times O u_{u d}+\sum_{e=1}^{E} \sum_{d=1}^{D} \sum_{m=1}^{M} V 2_{e d m} \times O e_{e m}+\sum_{y=1}^{Y} \sum_{d=1}^{D} \sum_{r=1}^{R} V 3_{y d r} \times O y_{y r} \\
& +\sum_{d=1}^{D} F_{d} B C_{d}+\sum_{m=1}^{M} F_{m} B C_{m}+\sum_{r=1}^{R} F_{r} B C_{r}+\sum_{t=1}^{T} \sum_{d=1}^{D} \sum_{l=1}^{L} V 6_{t d l} \times L C_{t l} \\
& +\sum_{u=1}^{U} \sum_{k=1}^{K} \sum_{d=1}^{D} V 1_{u k d} \times B_{k d} \times T u_{u}+\sum_{e=1}^{E} \sum_{d=1}^{D} \sum_{m=1}^{M} V 2_{e d m} \times B_{d m} \times T e_{e}+\sum_{y=1}^{Y} \sum_{d=1}^{D} \sum_{r=1}^{R} V 3_{y d r} \times B_{d r} \times T y_{y} \\
& +\sum_{t=1}^{T} \sum_{d=1}^{D} \sum_{l=1}^{L} V 4_{t d l} \times B_{d l} \times T t_{t}+\sum_{e=1}^{E} \sum_{m=1}^{M} \sum_{s=1}^{S} V 5_{e m s} \times B_{m s} \times T E_{e}+\sum_{y=1}^{Y} \sum_{r=1}^{R} \sum_{p=1}^{P} V 6_{y r p} \times B_{r p} \times T Y_{i y} \\
& -\sum_{e=1}^{E} \sum_{m=1}^{M} \sum_{s=1}^{S} V 5_{e m s} \times \operatorname{Re}_{e}-\sum_{y=1}^{Y} \sum_{r=1}^{R} \sum_{p=1}^{P} V 6_{y r p} \times R y_{y} \\
& +\sum_{u=1}^{U} \sum_{k=1}^{K} \sum_{d=1}^{D} V 1_{u k d} \times B_{k d} \times T u_{u} \times \frac{P O 1_{k d} \times C O 1_{k d}}{M a x\left(P O 1_{k d} \times C O 1_{k d}\right)}+\sum_{e=1}^{E} \sum_{d=1}^{D} \sum_{m=1}^{M} V 2_{e d m} \times B_{d m} \times T e_{e} \times \frac{P O 2_{d m} \times C O 2_{d m}}{M a x\left(P O 2_{d m} \times C O 2_{d m}\right)} \\
& +\sum_{y=1}^{Y} \sum_{d=1}^{D} \sum_{r=1}^{R} V 3_{y d r} \times B_{d r} \times T y_{y} \times \frac{P O 3_{d r} \times C O 3_{d r}}{\operatorname{Max}\left(P O 3_{d r} \times C O 3_{d r}\right)}+\sum_{t=1}^{T} \sum_{d=1}^{D} \sum_{l=1}^{L} V 4_{t d l} \times B_{d l} \times T t_{t} \times \frac{P O 4_{d l} \times C O 4_{d l}}{\operatorname{Max}\left(P O 4_{d l} \times C O 4_{d l}\right)} \\
& +\sum_{e=1}^{E} \sum_{m=1}^{M} \sum_{s=1}^{S} V 5_{e m s} \times B_{m s} \times T E_{e} \times \frac{P O 5_{m s} \times C O 5_{m s}}{\operatorname{Max}\left(P O 5_{m s} \times C O 5_{m s}\right)}+\sum_{y=1}^{Y} \sum_{r=1}^{R} \sum_{p=1}^{P} V 6_{y r p} \times B_{r p} \times T Y_{i y} \times \frac{P O 6_{r p} \times C O 6_{r p}}{\operatorname{Max}\left(P O 6_{r p} \times C O 6_{r p}\right)}
\end{aligned}
$$

$$
\begin{aligned}
& \sum_{k=1}^{K} V 1_{u k d} \leq F d_{d} \times C U_{u d}, \forall u, d \\
& \sum_{d=1}^{D} V 2_{e d m} \leq F m_{m} \times C E_{e m}, \forall e, m \\
& \sum_{d=1}^{D} V 3_{y d r} \leq F r_{r} \times C Y_{y r}, \forall y, r \\
& \sum_{d=1}^{D} V 4_{t d l} \leq C T_{t l}, \forall t, l \\
& \sum_{m=1}^{M} V 5_{e m s} \leq F m_{m} \times N e_{e s}, \forall e, s \\
& \sum_{r=1}^{R} V 6_{y r p} \leq F r_{r} \times N y_{y p}, \forall y, p \\
& F F_{d}, F F_{m}, F_{r}: b i n a r y \\
& V 1_{u k d}, V 2_{e d m}, V 3_{y d r}, V 4_{t d l}, V 5_{e m s}, V 6_{y r p} \geq 0
\end{aligned}
$$

Constraint (2) presents all used products are collected at collecting zones. The outcomes of disassembly facilities are described by constraints (3)-(5). Constraints (6)-(7) ensure the flow equivalence of different kinds at facilities. Constraints (8)-(11) require that a number of items at disassembly, remanufacturing, recycling facilities and disposal sites are not greater than the maximum capacity of these facilities. Constraints (12)-(13) make sure that the quantities of reusable and recycling materials do not exceed the maximum need of demand and secondary markets. Constraints (14)-(15) show the binary and integer variables.

\section{NUMERICAL EXAMPLE}

This section presents a numerical example to evaluate the practicability of the proposed model. In this example, two different types of used products are considered and the product structure tree of these used products are shown in Figures 2 and 3. There are one unit of reusable item $\left(E_{1}\right)$, two units of recycling materials $\left(\mathrm{Y}_{1}, \mathrm{Y}_{2}\right)$, and one unit of hazardous material $\left(\mathrm{T}_{1}\right)$ in used product $\mathrm{U}_{1}$ while there are one unit of reusable component $\left(\mathrm{E}_{2}\right)$, three units of recycling materials $\left(\mathrm{Y}_{3}, \mathrm{Y}_{4}, \mathrm{Y}_{5}\right)$ and one unit of hazardous material in used product $\mathrm{U}_{2}$.

In addition, there are two collection areas $\left(K_{l}, K_{2}\right)$, three potential locations for disassembly centers $\left(D_{1}, D_{2}, D_{3}\right)$, three potential locations for remanufacturing centers $\left(M_{1}, M_{2}, M_{3}\right)$, two secondary markets $\left(S_{1}, S_{2}\right)$, two demand markets $\left(P_{1}, P_{2}\right)$ and one disposal site $\left(L_{1}\right)$. These parameters (Tables 1-10) in the model are generated within a reasonable range and adopted from John et al. (2017) and Phuc et al. (2013). Table 1 presents the size of the numerical example while unit revenue received from recycled and reusable items is given in Table 2. The distance between centers is provided in Table 4 whereas the unit of transportation, operating, fixed costs are shown in Tables 3, 5 and 6, respectively. The maximum capacity at facilities is represented in Tables 7 and 8. Table 9 shows the number of used products at collection areas. It is assumed that the value of the probability and the consequence of accident occurrence from transportation between centers is in the scale of 1 to 10 adopted from El Dabee et al. (2013) as shown in Table 10.

Table 1 The size of the numerical example

\begin{tabular}{lllllllllll}
\hline $\mathbf{K}$ & $\mathbf{D}$ & $\mathbf{M}$ & $\mathbf{R}$ & $\mathbf{S}$ & $\mathbf{P}$ & $\mathbf{L}$ & $\mathbf{U}$ & $\mathbf{E}$ & $\mathbf{Y}$ & $\mathbf{T}$ \\
\hline 2 & 3 & 3 & 2 & 2 & 2 & 1 & 2 & 2 & 5 & 2 \\
\hline
\end{tabular}




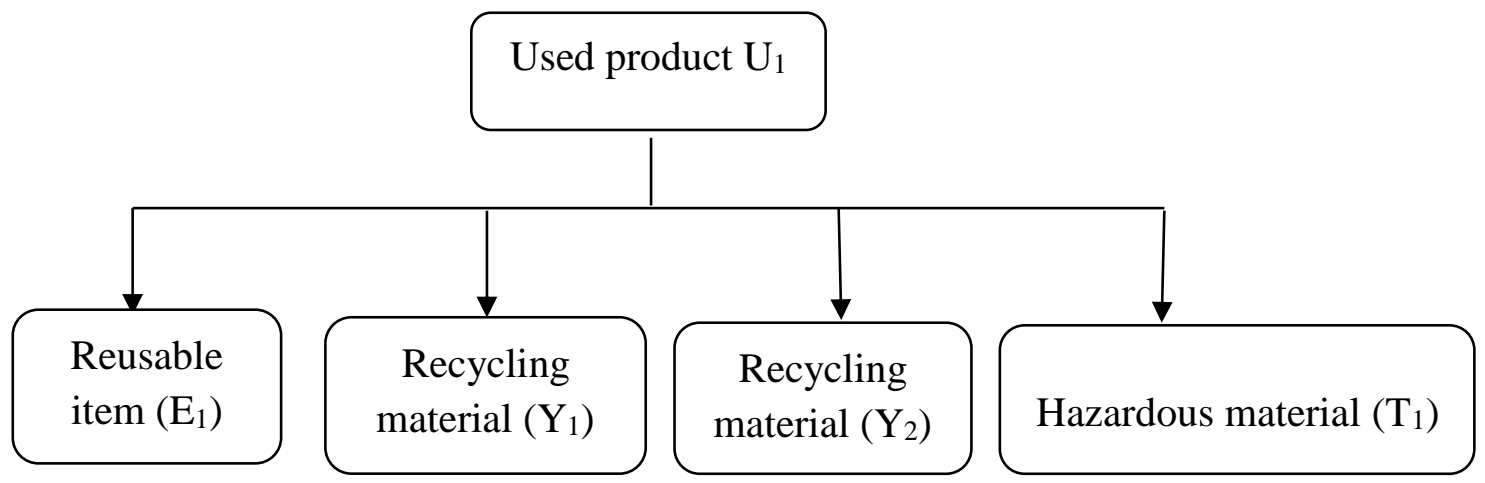

Figure 2 Product structure of used product $U_{1}$

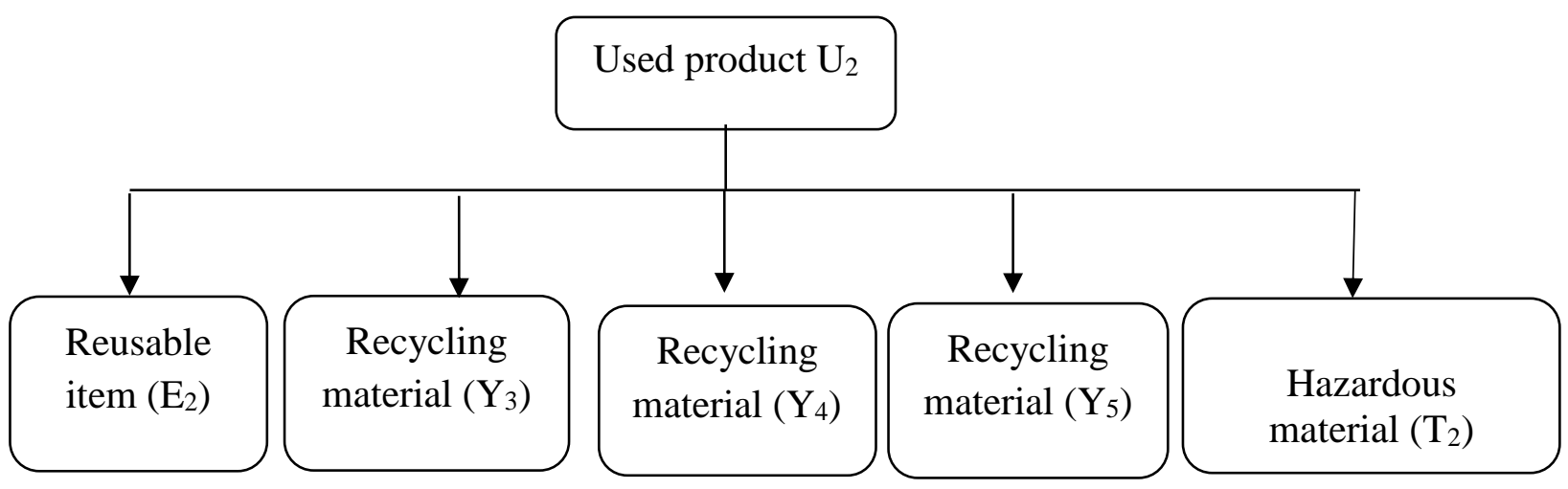

Figure 3 Product structure of used product $\mathrm{U}_{2}$

Table 2 Unit revenue received from recycled and reusable components (\$)
$\operatorname{Re}_{1} \operatorname{Re}_{2}$
$1.8 \quad 1.5$
$\begin{array}{llll}R y_{1} & R y_{2} & R y_{3} & R y_{4} \\ R y_{5}\end{array}$
$\begin{array}{lllll}2 & 1.8 & 1.6 & 1.6 & 2.3\end{array}$

Table 3 The unit transportation cost per $\mathrm{km}(\$)$

\begin{tabular}{|c|c|c|c|c|}
\hline & $\begin{array}{c}\text { Used } \\
\text { products }\end{array}$ & $\begin{array}{c}\text { Reusable } \\
\text { items }\end{array}$ & $\begin{array}{l}\text { Recycling } \\
\text { materials }\end{array}$ & Hazardous materials \\
\hline $\begin{array}{l}\mathrm{Tu}_{1} \\
2\end{array}$ & $\begin{array}{l}\mathrm{Tu}_{2} \\
1.6\end{array}$ & $\begin{array}{ll}\mathrm{Te}_{1} & \mathrm{Te}_{2} \\
0.5 & 0.4\end{array}$ & 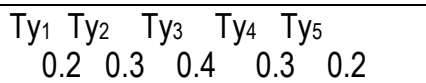 & $\begin{array}{cc}\mathrm{Tt}_{1} & \mathrm{Tt}_{2} \\
0.6 & 0.5\end{array}$ \\
\hline
\end{tabular}

Table 4 Distance between centers $(\mathrm{km})$

\begin{tabular}{l|lllllllll}
\hline Dist. & $\mathbf{K}_{\mathbf{1}}$ & $\mathbf{K}_{\mathbf{2}}$ & $\mathbf{M}_{\mathbf{1}}$ & $\mathbf{M}_{\mathbf{2}}$ & $\mathbf{M}_{\mathbf{3}}$ & $\mathbf{R}_{\mathbf{1}}$ & $\mathbf{R}_{\mathbf{2}}$ & $\mathbf{R}_{\mathbf{3}}$ & $\mathbf{L}_{\mathbf{1}}$ \\
\hline $\mathrm{D}_{1}$ & 20 & 20 & 34 & 36 & 39 & 37 & 43 & 42 & 23 \\
$\mathrm{D}_{2}$ & 22 & 26 & 25 & 38 & 30 & 40 & 42 & 44 & 28 \\
$\mathrm{D}_{3}$ & 32 & 37 & 28 & 30 & 33 & 38 & 39 & 42 & 24 \\
\hline Dist. & $\mathbf{S}_{1}$ & $\mathbf{S}_{\mathbf{2}}$ & Dist. & $\mathbf{P}_{\mathbf{1}}$ & $\mathbf{P}_{\mathbf{2}}$ & & & & \\
\hline $\mathrm{M}_{1}$ & 28 & 24 & $\mathrm{R}_{1}$ & 23 & 19 & & & \\
$\mathrm{M}_{2}$ & 27 & 26 & $\mathrm{R}_{2}$ & 24 & 26 & & & \\
$\mathrm{M}_{3}$ & 25 & 27 & $\mathrm{R}_{3}$ & 25 & 23 & & & & \\
\hline
\end{tabular}

$\underline{\text { Table } 5 \text { Operating cost at disassembly, recycling and remanufacturing centers (\$) }}$

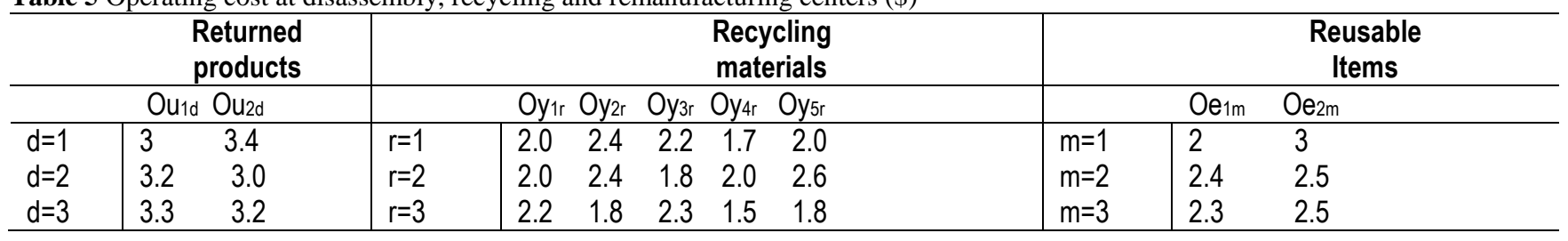


Table 6 Fixed cost for building disassembly, recycling and remanufacturing centers and disposal cost (\$)

\begin{tabular}{|c|c|c|c|c|c|c|c|c|}
\hline & $B C_{d}$ & & $\mathrm{BC}_{\mathrm{r}}$ & & $\mathrm{BC}_{\mathrm{m}}$ & & $L C_{11}$ & $\mathrm{LC}_{21}$ \\
\hline$d=1$ & 950 & $r=1$ & 750 & $m=1$ & 850 & $l=1$ & 3 & 2 \\
\hline$d=2$ & 920 & $r=2$ & 840 & $m=2$ & 800 & & & \\
\hline$d=3$ & 870 & $r=3$ & 800 & $m=3$ & 820 & & & \\
\hline
\end{tabular}

Table 7 Maximum capacity at disassembly, recycling and remanufacturing centers (unit)

\begin{tabular}{|c|c|c|c|c|c|c|c|c|c|c|c|}
\hline & $\mathrm{CU}_{1 \mathrm{~d}}$ & $\mathrm{CU}_{2 \mathrm{~d}}$ & & $\mathrm{CY}_{1 \mathrm{r}}$ & $\mathrm{CY}_{2 \mathrm{r}}$ & $\mathrm{CY}_{3 \mathrm{r}}$ & $\mathrm{CY}_{4 \mathrm{r}}$ & $C Y_{5 r}$ & & $C E_{1 \mathrm{~m}}$ & $\mathrm{CE}_{2 \mathrm{~m}}$ \\
\hline$d=1$ & 650 & 550 & $r=1$ & 642 & 746 & 868 & 953 & 864 & $m=1$ & 250 & 300 \\
\hline$d=2$ & 600 & 730 & $r=2$ & 920 & 836 & 924 & 826 & 790 & $m=2$ & 350 & 450 \\
\hline$d=3$ & 650 & 550 & $r=3$ & 1060 & 1480 & 467 & 470 & 440 & $m=3$ & & \\
\hline
\end{tabular}

$\underline{\text { Table } 8 \text { Maximum need at secondary markets, demand markets, and disposal site (unit) }}$

\begin{tabular}{|c|c|c|c|c|c|c|c|c|c|c|c|}
\hline & $\mathrm{Ne}_{1 \mathrm{~s}}$ & $\mathrm{Ne}_{2 \mathrm{~s}}$ & & $\mathrm{Ny}_{1 \mathrm{p}}$ & $\mathrm{Ny}_{2 \mathrm{p}}$ & $\mathrm{Ny}_{3 \mathrm{p}}$ & $\mathrm{Ny}_{4 \mathrm{p}}$ & $\mathrm{Ny}_{5 p}$ & & $\mathrm{CT}_{11}$ & $\mathrm{CT}_{21}$ \\
\hline$s=1$ & 860 & 700 & $p=1$ & 550 & 650 & 500 & 520 & 680 & $\mathrm{I}=1$ & 1500 & 820 \\
\hline$s=2$ & 900 & 520 & $p=2$ & 840 & 640 & 527 & 674 & 730 & & & \\
\hline
\end{tabular}

Table 9 The number of used products at collection areas (unit)

$$
\text { Nuk }
$$

\begin{tabular}{l|ll}
\hline $\mathbf{k}$ & $\mathbf{1}$ & $\mathbf{2}$ \\
\hline 1 & 350 & 460 \\
2 & 250 & 340 \\
\hline
\end{tabular}

Table 10 The probability and the consequence of accident occurrence from transportation between centers

\begin{tabular}{|c|c|c|c|c|c|c|}
\hline & \multicolumn{2}{|c|}{$\begin{array}{l}\text { Probability } \\
(1-10)\end{array}$} & & \multicolumn{2}{|c|}{$\begin{array}{l}\text { Consequence } \\
(1-10)\end{array}$} & \\
\hline Route k-d & P01 1d & $\mathrm{PO}_{2 \mathrm{~d}}$ & & $\mathrm{CO} 1_{1 \mathrm{~d}}$ & $\mathrm{CO}_{2 \mathrm{~d}}$ & \\
\hline$d=1$ & 2 & 2 & & 2 & 3 & \\
\hline$d=2$ & 2 & 2 & & 2 & 3 & \\
\hline$d=3$ & 1 & 1 & & 2 & 2 & \\
\hline Route d-m & $\mathrm{PO} 21 \mathrm{~m}$ & $\mathrm{PO} 22 \mathrm{~m}$ & $\mathrm{PO} 23 \mathrm{~m}$ & $\mathrm{CO} 21 \mathrm{~m}$ & $\mathrm{CO} 2 \mathrm{~m}$ & $\mathrm{CO} 23 \mathrm{~m}$ \\
\hline$m=1$ & 3 & 2 & 1 & 2 & 2 & 2 \\
\hline$m=2$ & 2 & 2 & 1 & 1 & 2 & 1 \\
\hline$m=3$ & 2 & 2 & 1 & 1 & 1 & 1 \\
\hline Route d-r & $\mathrm{PO} 3_{1 \mathrm{r}}$ & $\mathrm{PO}_{2 r}$ & $\mathrm{PO}_{3 r}$ & $\mathrm{CO}_{11 \mathrm{r}}$ & $\mathrm{CO}_{2 \mathrm{r}}$ & $\mathrm{CO}_{3 r}$ \\
\hline$r=1$ & 2 & 1 & 1 & 2 & 3 & 2 \\
\hline$r=2$ & 4 & 2 & 4 & 3 & 2 & 3 \\
\hline$r=3$ & 3 & 3 & 2 & 1 & 2 & 2 \\
\hline Route d-I & $\mathrm{PO}_{11}$ & $\mathrm{PO}_{2 \mid}$ & $\mathrm{PO}_{31}$ & $\mathrm{CO}_{11}$ & $\mathrm{CO}_{21}$ & $\mathrm{CO}_{31}$ \\
\hline $\mid=1$ & 4 & 3 & 2 & 2 & 2 & 3 \\
\hline Route m-s & $\mathrm{PO}_{1 \mathrm{~s}}$ & $\mathrm{PO}_{2 \mathrm{~s}}$ & $\mathrm{PO}_{3 \mathrm{~s}}$ & $\mathrm{CO}_{1 \mathrm{~m}}$ & $\mathrm{CO}_{2 \mathrm{~m}}$ & $\mathrm{CO}_{3 \mathrm{~m}}$ \\
\hline$s=1$ & 3 & 2 & 1 & 2 & 3 & 1 \\
\hline$s=2$ & 3 & 2 & 1 & 3 & 3 & 1 \\
\hline Route $r-p$ & $P 06_{1 p}$ & $\mathrm{PO}_{2 p}$ & $\mathrm{PO6}_{3 p}$ & $\mathrm{CO6}_{1 \mathrm{p}}$ & $\mathrm{CO}_{2 p}$ & $\mathrm{CO}_{3 p}$ \\
\hline$p=1$ & 2 & 4 & 2 & 2 & 3 & 2 \\
\hline$p=2$ & 1 & 2 & 2 & 2 & 2 & 2 \\
\hline
\end{tabular}

The proposed model is solved by an optimization software to find the optimal solution. There are two cases considered in the study. With risk cost (case 1), the total cost obtained is $\$ 52371$. On the other hand, the result is $\$ 44159$ without risk cost (case 2). The results also indicate that the treatment centers $\left(D_{1}, D_{2}, M_{1}, M_{3}, R_{2}\right.$, and $\left.R_{3}\right)$ should be opened in case 1 while $D_{1}, D_{2}, M_{1}, M_{2}, R_{2}$, and $R_{3}$ should be utilised in case 2 . It can be seen that $R_{1}$ and $\mathrm{D}_{3}$ are not selected in both cases since the disassembly centers $\left(D_{1}, D_{2}\right)$ and recycling centers $\left(R_{2}, R_{3}\right)$ are sufficient to handle used products and components with cost minimization. However, there is a difference in remanufacturing centers chosen in two cases. $\mathrm{M}_{1}$ and $\mathrm{M}_{3}$ are selected in case 1 while $\mathbf{M}_{1}$ and $\mathbf{M}_{2}$ are chosen in case 2. Consequently, there are some changes in the movement of items and materials in the RSC network $\left(\mathrm{V} 1_{\mathrm{ukd}}, \mathrm{V} 2_{\mathrm{edm}}\right.$, $\mathrm{V} 3_{\mathrm{ydr}}$, and $\mathrm{V} 4_{\mathrm{tdl}}$ ) in the two cases (as seen in Figures 4 and 5 ). For example, as can be seen in the second stage, 250 units of $2^{\text {nd }}$ used product are delivered from $D_{2}$ to $M_{1}$ in case 2 while this figure rises to 330 units shipped from $D_{2}$ to $M_{1}$ in case 1 . The main reason is that the risk cost from $D_{1}$ to $M_{1}$ is higher than that from $D_{2}$ to $M_{1}$. Hence, it is better to increase the number of used products delivered from $\mathrm{D}_{1}$ to $\mathrm{M}_{1}$ in order to reduce the total cost. 
The results in the example clearly show that the transportation risk is one of the major factors in terms of the total cost and RSC network designs. In the numerical example, the total cost increases more than $18 \%$ with risk cost incorporated. In addition, the flow of materials or items can be considerably changed when transportation risk is considered (as shown in Figures 4 and 5). Thus, it can be concluded that it is necessary to include transportation risk in the model to represent the real RSC.

A RSC system generally needs a large initial investment for constructing dismantling, remanufacturing, and recycling facilities. Hence, one of the key issues in a RSC that decision makers are facing is the determination of the number and location of different centers, as well as the optimal flow of materials and components through the network. The proposed mathematical model suggests the optimal decisions to establish a RSC network design while transportation risk is incorporated. Furthermore, each kind of waste has transferred to different treatment processes based on its characteristic. Therefore, the proposed model presented in this study has practical implications for the network design of an e-waste RSC.

\section{CONCLUSIONS}

A multi-product and multi-tier RSC model for ewaste with consideration of transportation risk has been developed in this paper. This model is to optimize the total cost of RSC system while considering transportation risk. The example shows that there is a considerable difference in the comparison of two cases (case 1- with risk cost and case 2- without risk cost). The results also show that the movement of items and materials can be significantly affected by risk cost.

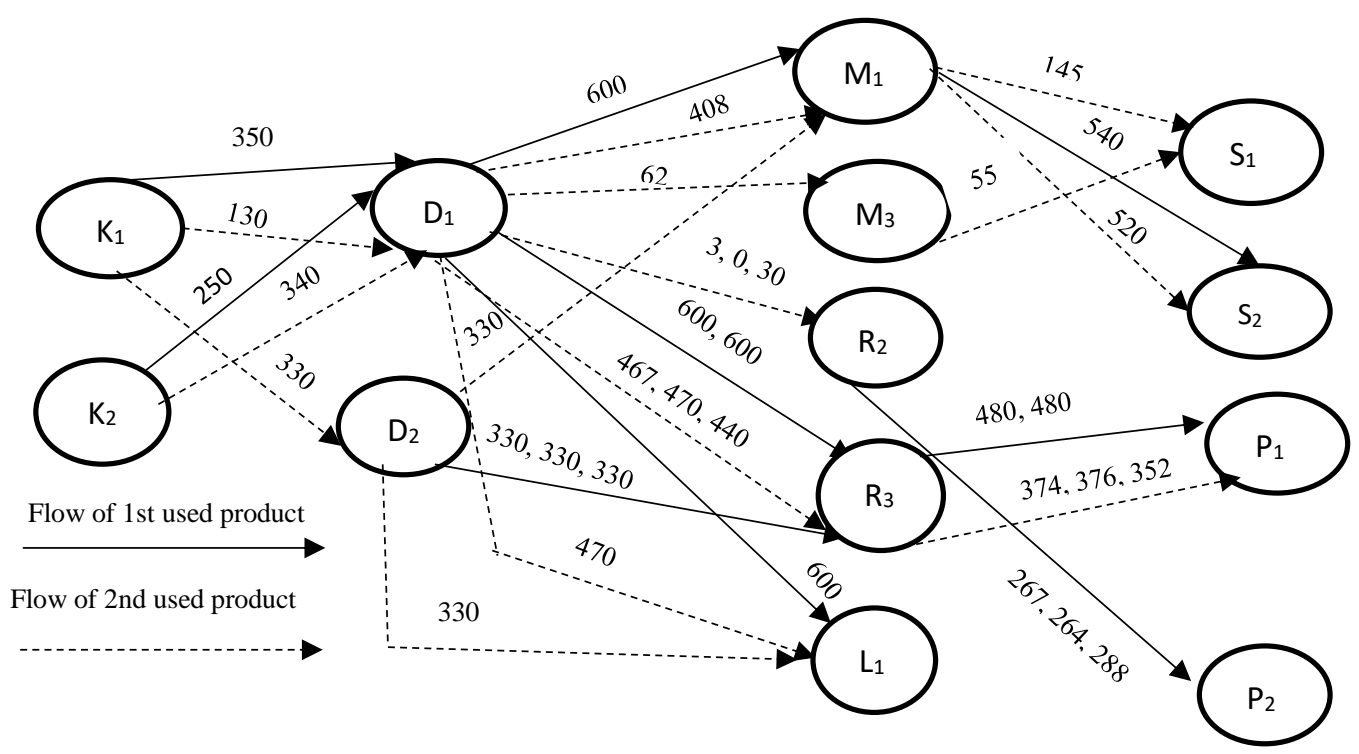

Figure 4 The flow of items and materials with considering risk cost (case 1)

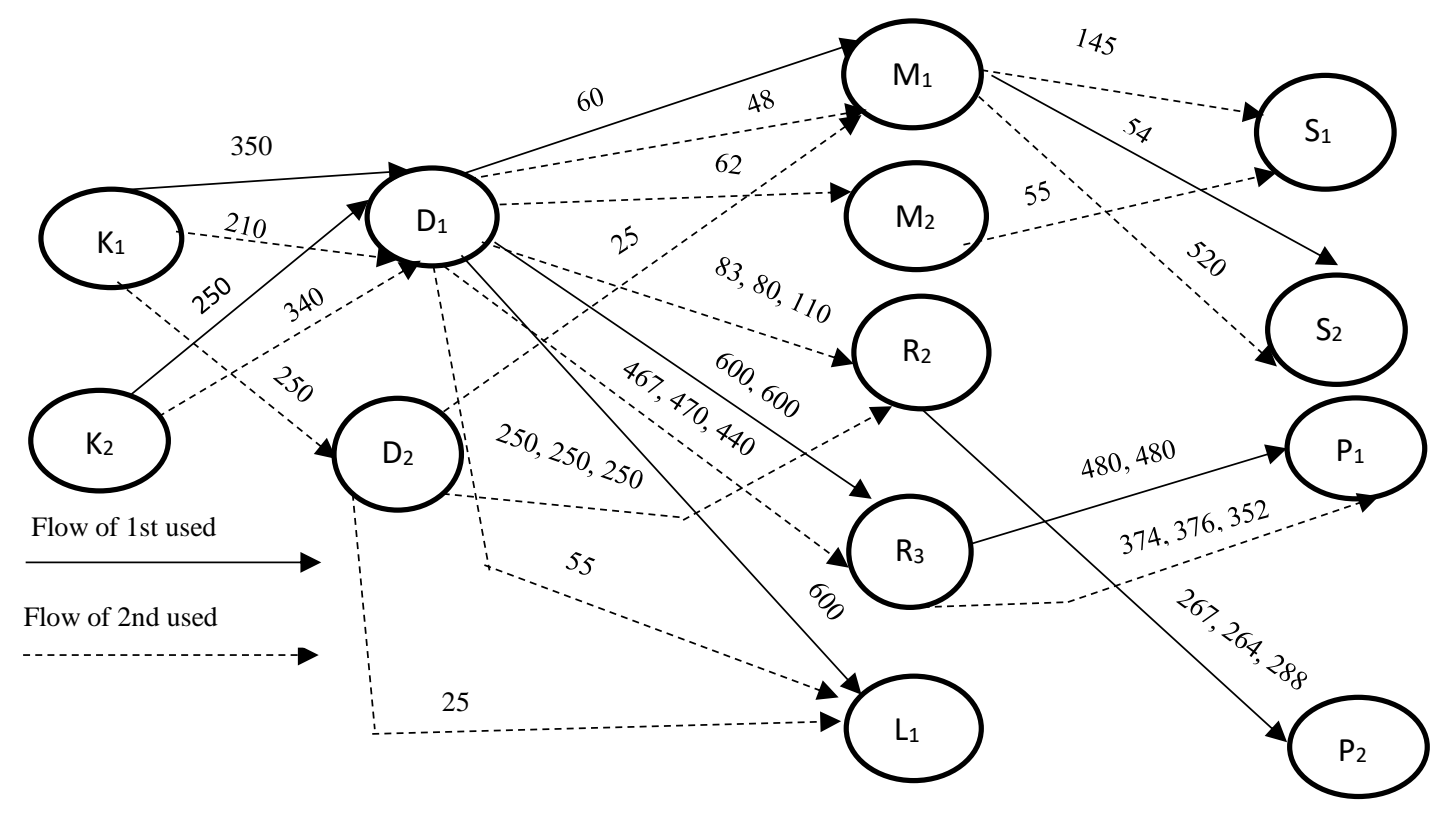

Figure 5 The flow of items and materials without considering risk cost (case 2) 
The proposed model in this paper can be a good starting point for further studies in the field of RSC network designs with integrating risk cost. This paper can assist managers to have a better perception in establishing e-waste RSC system in consideration of risk factors in order to achieve the desired goal.

However, there are some limitations in this research that are waiting for further research. Firstly, it is assumed that the amount of returned products and the cost are deterministic in this paper but in reality, these parameters are uncertain. Therefore, stochastic or fuzzy approaches should be developed to deal with such uncertain elements. Secondly, the proposed model only considers transportation risk, and hence other risks in the RSC operation such as demand risk, processing risk, or environmental risk need to be incorporated in the future research to establish a more comprehensive model for the real e-waste RSC system.

\section{ACKNOWLEDGEMENTS}

The first author would like to thank the Australian Government for sponsoring her $\mathrm{PhD}$ program at University of South Australia, Australia under an Endeavour Award.

\section{REFERENCES}

Chandiran, P. (2014). Optimization of Inventory for Two Level Multiple Retailers-Single Manufacturer Reverse Supply Chain. Operations and Supply Chain Managment: An International Journal, 7(1), pp. 32-37.

Cucchiella, F., D'adamo, I., Lenny Koh, S. C. \& Rosa, P. (2015). Recycling of WEEEs: An economic assessment of present and future e-waste streams. Renewable and Sustainable Energy Reviews, 51, pp. 263-272.

Dabee, F. E., Marian, R. \& Amer, Y. (2013). A novel optimization model for simultaneous cost-risk reduction in multi-suppliers just-in-time systems. Journal of Computer Science, 9 (12), pp. 1778-1792.

Dat, L. Q., Truc Linh, D. T., Chou, S.-Y. \& Yu, V. F. (2012). Optimizing reverse logistic costs for recycling end-of-life electrical and electronic products. Expert Systems with Applications, 39(7), pp. 6380-6387.

Dowlatshahi, S. (2000). Developing a theory of reverse logistics. Interfaces, 30 (3), pp.143-155.

Dwivedy, M. \& Mittal, R. K. (2010) Estimation of future outflows of e-waste in India. Waste Management, 30 (3), pp. 483-491.

Eldabee, F. F. (2015). A Robust Optimisation Framework for the Simultaneous Cost-risk Reduction in Just-in-time Systems. University of South Australia.

Fabiano, B., Currò, F., Palazzi, E. \& Pastorino, R. (2002). A framework for risk assessment and decision-making strategies in dangerous good transportation. Journal of Hazardous Materials, 93 (1), pp. 1-15.

Fleischmann, M., Beullens, P., Bloemhof-Ruwaard, J. M. \& Wassenhove, L. N. (2001). The impact of product recovery on logistics network design. Production and operations management, 10 (2), pp. 156-173.

Gomes, M. I., Barbosa-Povoa, A. P. \& Novais, A. Q. (2011). Modelling a recovery network for WEEE: A case study in Portugal. Waste Management, 31(7), pp.1645-1660.

Govindan, K. \& Soleimani, H. (2017). A review of reverse logistics and closed-loop supply chains: a Journal of Cleaner Production focus. Journal of Cleaner Production, 142, Part 1, pp. 371-384.

John, S. T. \& Sridharan, R. (2015). Modelling and analysis of network design for a reverse supply chain. Journal of Manufacturing Technology Management, 26 (4), pp. 853-86.

John, S. T., Sridharan, R. \& Kumar, P. R. (2017). Multi-period reverse logistics network design with emission cost. International Journal of Logistics Management, 28 (1), pp. 127-149.

Kiddee, P., Naidu, R. \& Wong, M. H. (2013). Electronic waste management approaches: An overview. Waste Management, 33 (5), pp.1237-1250.

Kilic, H. S., Cebeci, U. \& Ayhan, M. B. (2015). Reverse logistics system design for the waste of electrical and electronic equipment (WEEE) in Turkey. Resources, Conservation and Recycling, 95, pp. 120-132.

Kumar, S. K., Tiwari, M. \& Babiceanu, R. F. (2010). Minimisation of supply chain cost with embedded risk using computational intelligence approaches. International Journal of Production Research, 48 (13), pp. 3717-3739.

Mahmoudi, H. \& Fazlollahtabar, H. (2014). An integer linear programming for a comprehensive reverse supply chain. Cogent Engineering, volume 1 (1), pp.1-14.

Manoj Hudnurkar, S. D., Urvashi Rathod, Suresh K. Jakhar (2017). Supply Chain Risk Classification Schemes: A Literature Review. Operations and Supply Chain Managment: An International Journal, 10 (4), pp.182-199.

Min, H. \& Ko, H.-J. (2008). The dynamic design of a reverse logistics network from the perspective of third-party logistics service providers. International Journal of Production Economics, 113 (1), pp. 176-192.

Nagalingam, S. V., Kuik, S. S. \& Amer, Y. (2013). Performance measurement of product returns with recovery for sustainable manufacturing. Robotics and Computer-Integrated Manufacturing, 29 (6), pp. 473-483.

Phuc, P. N. K., Yu, V. F. \& Chou, S.-Y. (2013). Optimizing the fuzzy closed-loop supply chain for electrical and electronic equipments. International Journal of Fuzzy Systems, 15 (1), pp. 9-21.

Pishvaee, M. S., Kianfar, K. \& Karimi, B. (2010). Reverse logistics network design using simulated annealing. The International Journal of Advanced Manufacturing Technology, 47(1), pp. 269-281.

Rahman, S. \& Subramanian, N. (2012). Factors for implementing end-of-life computer recycling operations in reverse supply chains. International Journal of Production Economics, 140 (1), pp. 239-248.

Rogers, D. S., Melamed, B. \& Lembke, R. S. (2012). Modeling and analysis of reverse logistics. Journal of Business Logistics, 33 (2), pp. 107-117.

Sheu, J.-B. (2007). A coordinated reverse logistics system for regional management of multi-source hazardous wastes. Computers \& Operations Research, 34 (5), 1442-1462.

Singh, N., Li, J. \& Zeng, X. (2016). Global responses for recycling waste CRTs in e-waste. Waste Management, 57, pp. 187-197.

Sohani, N. \& Chaurasia, M. K. (2016). Analysis of Risk Management for Reverse Supply Chain Network. Imperial Journal of Interdisciplinary Research, 2 (8), pp. 413-415.

Sthiannopkao, S. \& Wong, M. H. (2013). Handling e-waste in developed and developing countries: Initiatives, practices, and consequences. Science of The Total Environment, 463464, pp. 1147-1153.

Thun, J.-H. \& Hoenig, D. (2011). An empirical analysis of supply chain risk management in the German automotive industry. International Journal of Production Economics, 131(1), pp. 242-249.

Yanık, S. (2015). Reverse logistics network design under the risk of hazardous materials transportation. Human and Ecological Risk Assessment: An International Journal, 21 (5), pp. 1277 1298. 
Linh Thi Truc Doan received a master degree in industrial management from National Taiwan University of Science and Technology (NTUST), Taiwan. She is currently a Ph. D student of the School of Engineering in University of South Australia. Her interest is to research in project management, supply chain management, especially reverse supply chain. She is working in a comprehensive reverse supply chain model for Electronic waste (e-waste).

Yousef Amer holds a Ph.D. in mechanical and manufacturing engineering from the School of Engineering, University of South Australia. Currently, he is a Program Director in the School of Engineering, University of South Australia. He has 18 years' experience in automation, manufacturing, operations, logistics and supply chain management in various firms in Adelaide, both global and local. His research interests include simulation-based Lean Six-Sigma and Design for Six-Sigma, Artificial Intelligence, Manufacturing Strategy and Technology, Sustainability in Product and Service development, Lean and Green Supply Chain Modelling, Optimisation and Simulation and Sustainable Nano-manufacturing. He has published books and many papers in academic journals, including International Journal of Production Economic, International Journal of Production Research, and Robotics and Computer-Integrated Manufacturing.

Sang Heon Lee received a B.ESc degree in aeronautical engineering from Inha University Korea, and M.ESc in mechatronics from the University of New south Wales, and a Ph.D. degree in System Engineering from Australian National University. He is currently a program director and a senior lecturer in the School of Engineering, the University of South Australia. His current research focus is on development of efficient algorithm for green supply chain and digital image processing in agricultural and medical applications. His main research interests are in the area of discrete-event systems, fuzzy logic control and neural networks. He has published over 100 papers in academic journals and conference publications.

Phan Nguyen Ky Phuc received PhD degree at Industrial Management department from National Taiwan University of Science and Technology (NTUST), Taiwan. He is currently a lecturer at Ho Chi Minh City International University, Viet Nam. His recent research interests include reverse supply chain, inventory management, ranking fuzzy numbers, dynamic programming, meta-heuristic algorithm. 